\title{
Who Should Be An Author?
}

"A writer is someone for whom writing is more difficult than it is for other people."

Thomas Mann, German Novelist (1875-1955)

\subsection{Who Is an Author?}

An author is a person who creates a manuscript or paper. He is the one who initiates the process of crafting the document. He is also called a writer, a person who begins the process or plan or an idea [1]. Before venturing into the authorship of biomedical research, one should know if one is entering 'a sweet fruit of inspiration' or drifting 'towards a bitter fruit of the trade' [2]. Stephen Lock has summed up authorship as not being 'a bread ticket; it is an intellectual responsibility'. Incidence of inappropriate authorship even in Cochrane reviews has increased [3]. 


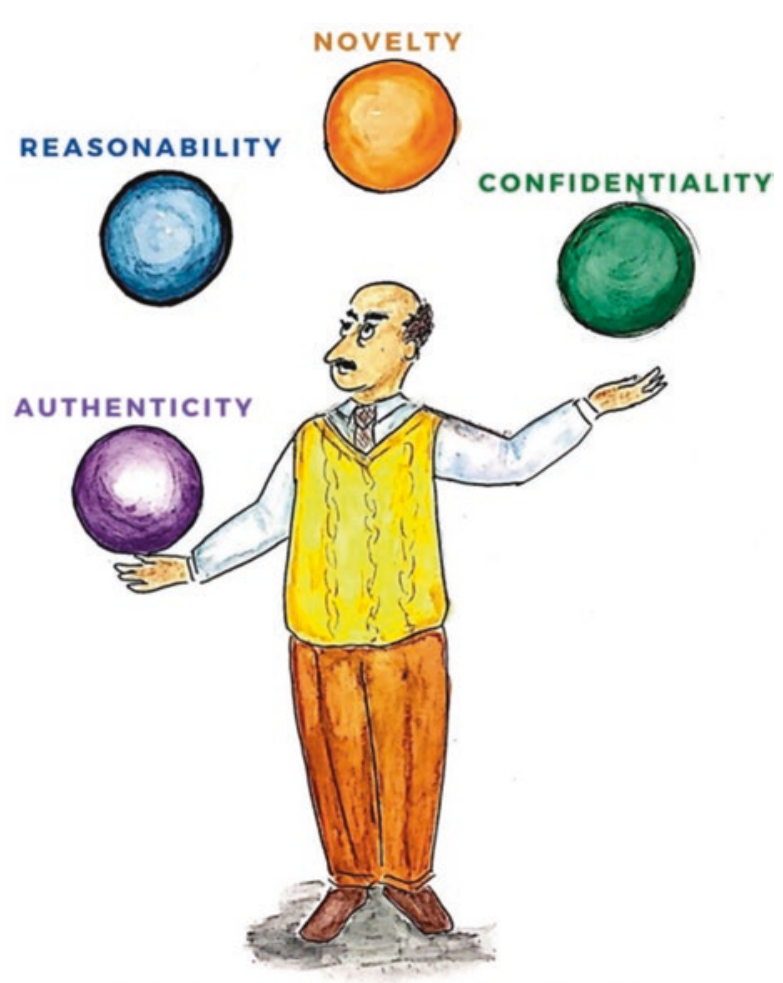

DUTIES OF AN AUTHOR

\subsection{Who Can Become an Author?}

Various journals have different criteria for defining 'who can be an author'. However, the majority now use the standard definition as given by the International Committee of Medical Journals (ICMJE) Editors, formerly called the 'Vancouver group'. The criteria for being an author included in this are related to study design, conception of the idea, data analysis, drafting of the manuscript, and final approval of the paper [4]. In 2013, a new version of this recommendation added as mandatory criteria-a declaration of conflict of interest, responsibility of the corresponding author, deciding who can become an author before the paper is conceived, and giving precision to the study question [5]. In addition to being accountable for the publication work, an author should be able to identify which co-authors are responsible for the other specific parts of the publication. These criteria as given in Table 14.1. 
Table 14.1 Defining the role as an author (ICMJE recommendation)

The authorship be based on the following criteria:

1. Substantial contributions to the conception or design of the work; or the acquisition, analysis, or interpretation of data for the work

AND

2. Drafting the work or revising it critically for important intellectual content AND

3. Final approval of the version to be published AND

4. Agreement to be accountable for all aspects of the work in ensuring that questions related to the accuracy or integrity of any part of the work are appropriately investigated and resolved

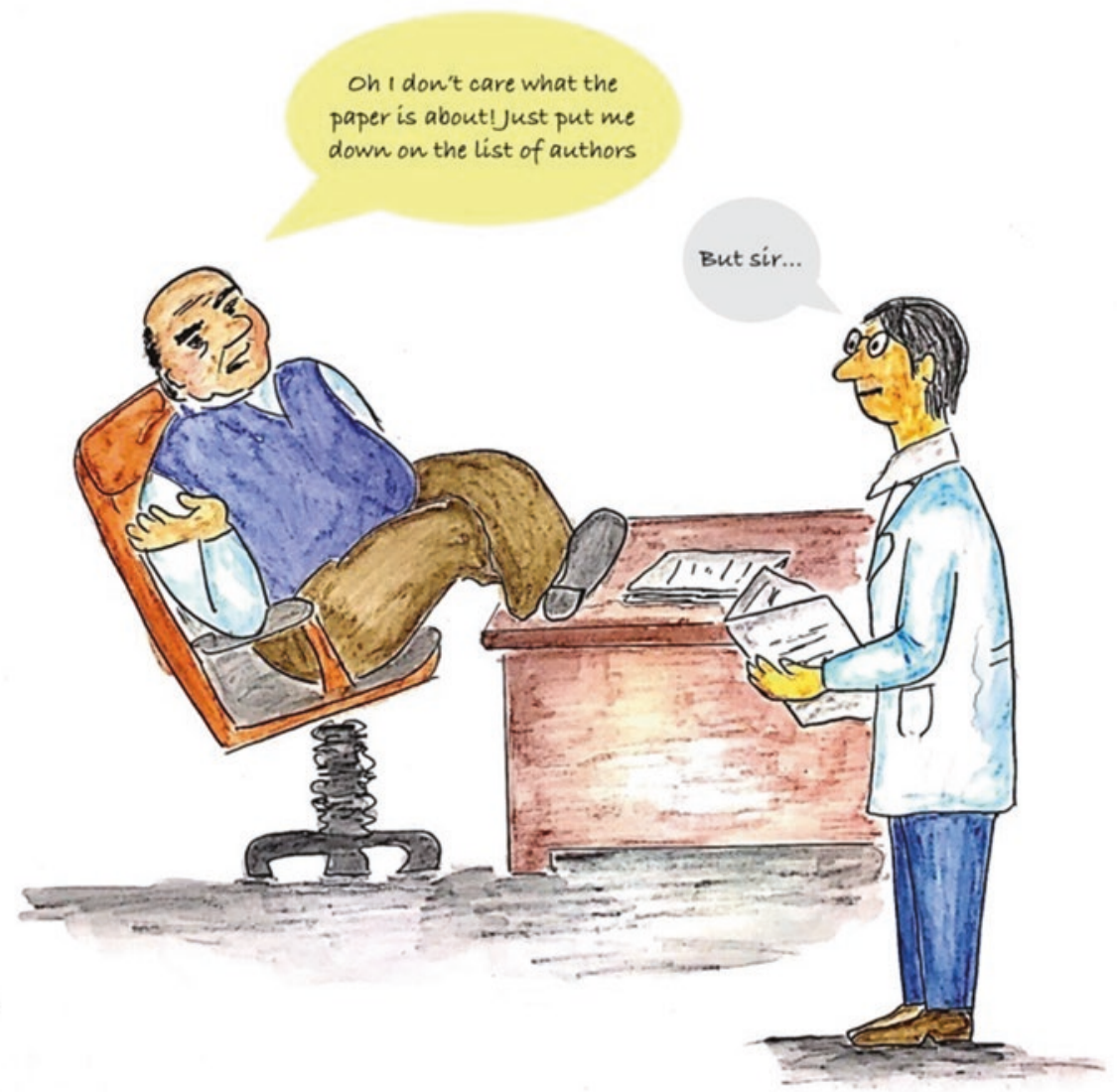




\subsection{Who Can We Acknowledge in a Scientific Paper?}

Any person who has not qualified as an author but has contributed intellectually to the study can be acknowledged. These may include people who have arranged for funding, generally supervised the research activities and administration, provided typing assistance, and done technical editing, language editing, or proofreading. The ICMJE encourages written permission from acknowledged individuals 'because acknowledgment may imply endorsement'. The acknowledgement is usually placed at the end of the conclusion section.

\subsection{Who Are Lead Authors and Co-authors?}

A lead author is also called the first/principal author and is the one who conducts the investigation as well as writes and edits the document. The co-author is someone who collaborates with the lead author and contributes to the work in the text [6].

\subsection{What Is the Corresponding Author?}

The corresponding author is the guarantor of the study, who communicates with the editors on behalf of the other authors. He is usually the senior most and is responsible for his team. He is a bridge between the authors and the journal. The functions of the corresponding author are [5]:

Being

- Responsible for the manuscript as it passes through the entire publication process

- The chief contact between the journal and co-authors

- Responsible for guaranteeing that all authors have reviewed and approved the final version of the paper prior to submission

- The author who uploads the paper for online submission and for peer review

- Responsible for dealing with communications from the journal (e.g., decision letters, reviewers' reports)

- Responsible for ethics committee approval and clinical trial registration

- Available throughout the submission and peer-review process to respond to editorial queries

- Available after publication to respond to critiques of the work

- Available to cooperate with any requests from the journal for data or additional information should questions about the paper arise after publication

\subsection{What Are the Types of Inappropriate Authorship?}

There are three types of inappropriate authorship. They are called guest authorship, gift authorship, and ghost authorship [7-9]. Sometimes, the 'guest and gift' are also referred to as 'honorary authors' as there is very little difference between them [10, 11]. 
The problem with including these authors is that the integrity of the work becomes questionable and it may also have an adverse effect on whether or not the submission is accepted. Honorary authorship is totally unethical and dilutes the credits which an honest writer should be getting. Articles with over five authors are more likely to have 'honorary authors' than those with three or fewer authors [12].

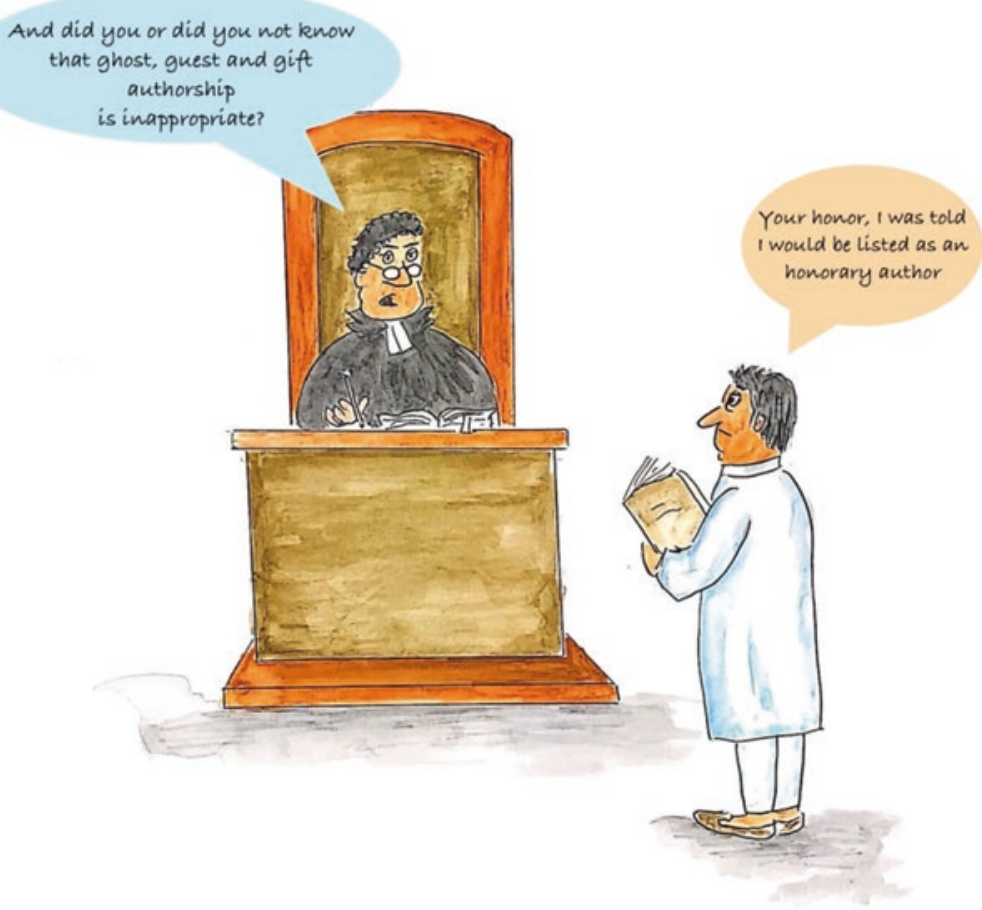

\subsection{What Is a Gift Author?}

Gift authorship is given to any senior in the department, chair of an organization, institutional head, or head of department. This person has not contributed to the conception of the manuscript but the junior fellow includes his name as a 'mark of respect'. Such passive noncontributors should not be included in the list of authors.

\subsection{What Is a Guest Author?}

Usually, an influential person whose name is included in an attempt to make the journal editor biased towards publication. 


\subsection{What Is a Ghost Author?}

Ghost authors are very common in some research work especially clinical trials. These are of three types:

- The name of a junior faculty member is omitted on purpose when the major work might have been done by him, thus robbing him of authorship credit.

- In the second type, the manuscript was prepared by a person only for financial gain and this person did not want this name to be included in the paper.

- The third type is the writer of a manuscript who is employed by a company which, e.g., sponsors a drug trial to get financial gain but whose name is not included in the list of authors.

\subsection{Are These Inappropriate Authors Common in the Scientific World?}

Inappropriate authorship is becoming very common globally and its reported prevalence is estimated to be $9-60 \%$ in different studies. Shah et al. reported the ugly side of research in India and reported the prevalence of honorary authorship to be $20.9 \%$ in India. The World Association of Medical Editors (WAME) labels ghostwriting to be a 'dishonest and unacceptable' act [15]. Table 14.2 depicts this data.

\subsection{What Are the Other Types of Authorship Misconduct?}

Coerced author: In this, the senior faculty forces his junior colleague to include his name in the research work. This senior researcher may have contributed absolutely nothing to the research findings [17-19].

Mutual support authorship: This act of bestowing authorship is carried out by mutual cooperation and agreement by authors to include each other's names in scientific manuscripts to achieve higher credits [16, 17].

Table 14.2 Prevalence of inappropriate authorship

\begin{tabular}{l|l|l}
\hline Author & Type of publication & Prevalence rates \\
\hline Moswatt et al. [3] & Cochrane review article authors & $39 \%$-Honorary authors \\
\hline & & $9 \%$-Ghost authors \\
\hline Flanagin et al. [13] & Review articles & $26 \%$-Honorary authors \\
\hline Shah et al. [14] & Leading Medical and Dental & $20.9 \%$ Honorary \\
\hline & Institutes in India & \\
\hline Ghajarzadesh [15] & Asia data & $32.17 \%$-Gift \\
\hline Bates et al. [12] & & JAMA, BMJ \\
\hline & Annals of Internal Medicine & $60 \%$-Honorary author \\
\hline
\end{tabular}


Duplicate authorship: This is an act of publishing identical manuscripts in more than one journal with different headings to increase the number of publications in the curriculum vitae $[17,20]$.

Forged authorship: In this, the author is unaware of his name being included. He has not taken part in the research or manuscript writing, reviewing, or drafting, but is awarded a place in authorship without his knowledge or consent to increase the chances of the paper being accepted by a peer-reviewed journal [21].

Orphan authorship: These are the authors who had contributed considerably to the work, but are omitted from the list of authors of the manuscript [21].

Denial of authorship: This is a dreadful form of authorship abuse in which a paper of research work carried out by others is submitted to a journal without providing the credit to core searchers in the form of an authorship and acknowledgement $[17,22]$.

\subsection{What Is CRediT?}

This means contributor Roles Taxonomy (CRediT). It is based on 14 different criteria and will permit authors to provide information on the author's individual contributions to the manuscript. Few of the important aspects are Conceptualization, Data Curation, Formal Analysis, Funding Acquisition, Validation, Visualization, WritingOriginal Draft Preparation, Writing-Review \& Editing. Each of these has a stated definition and helps to classify the authors according to various duties [23, 24].

\subsection{How Does One Decide Authorship Issues in Multicentre Trials?}

When a large, multicentre group has conducted the work the group should identify the individuals who accept direct responsibility for the manuscript. These individuals should fulfil the criteria for authorship defined above and editors should ask for individuals to complete the contribution of each one and also fill up a conflict-ofinterest disclosure forms. The corresponding author should clearly indicate the preferred citation sequence. The Acknowledgements should be spelled out at the time of submission [5].

\subsection{Who Settles the Dispute Post Publication of Authorship?}

When authorship disputes arise after publication, most current guidelines recommend that the authors work out the disputes between themselves. But this is unlikely to occur because there are often large power disparities between team members and institutions (e.g., universities, funding agencies) are unlikely to have authority over all team members [25]. 


\subsection{What Is Retraction Watch?}

RetractionWatch.com is a public website launched in 2010. It gives information about articles which have been retracted and the possible reasons. There have been more than 700 cases where manuscripts have been withdrawn due to authorship problems [26].

\subsection{What Is the Responsibility of a Journal Regarding Authorship?}

The journals should spread awareness about authorship criteria so that potential writers do not default [11]. Table 14.3 mentions few steps that journals can take.

\subsection{What Are Remedial Measures for Authorship Abuse?}

These can be grouped into non-judicial or judicial measures. The non-judicial measures are withdrawing the paper and black listing the authors [2]. For the judicial approach a person can use various sections of the Indian penal court like section 62 , section55 and section 63. Journals can also take these actions according to ICMJE [5].

Several actions are possible:

1. To serve a notice that a paper has been ghostwritten, along with the names of the responsible companies and the submitting author

2. To make the authors' academic institution aware of this incident

3. To identify the commercial companies involved in such an act

4. To provide specific names if contacted by the popular media or government organizations

5. To share their experiences on the World Associations of Medical Editors (WAME) Listserve and in other forums.

Table 14.3 What measures journals can take to prevent guest authorship?

Providing directions to authors regarding authorship criteria by listing them in their "Instructions to Authors'

Pledging allegiance to the authorship criteria provided by the ICMJE

Requiring each author to sign that he or she fulfils the authorship criteria

Requiring authors to commit that no one who satisfies authorship criteria has been excluded and no one who does not qualify as an author has been included

Declaration from all authors about the exact contribution made to the conduct of the research and in preparation and finalization of the manuscript

Keeping the number of authors permitted to a pre-set number 


\subsection{How Many Co-authors Should There Usually Be in a Research Paper?}

It is not the number of authors but the quality of the paper that is the most important factor. If the author has significantly contributed to the manuscript his name should be included. In 1981, the maximum number of authors on any paper indexed by Clarivate Analytics was 118. In 2006, this number was 2500, which in the next 2 years reached 3000 authors for a paper. Currently, a physics paper holds the record for the largest number of authors, i.e., 5154 authors for a single paper [27].

Persons or groups who have aided the research study but whose contributions do not justify being authors may be listed under such headings as 'participating investigators' or 'clinical investigators'. These people should give written permission to be acknowledged, because readers may argue their endorsement of the data and conclusions [28].

\subsection{What Is the Meaning of Shared First Co-author?}

Shared co-first authorship is defined as 'two or more authors who have worked together on a publication and contributed equally. This equal contribution is often indicated in the fine print of a published paper or in an investigator's curriculum vitae'. A few journals publish the manuscript mentioning shared co-authorship in the description of the author's contribution. For example, Gastroenterology mentions up to two co-first authors by printing their names in bold letters in the reference section but not in the body of the manuscript. There is no uniform format for a citation for the first co-author [29].

\subsection{Conclusions}

- Authors are fully responsible for the intellectual content of the manuscript. The International Committee of Medical Journals (ICMJE) recommends that authorship be based on certain fixed criteria.

- Persons who have helped in the technical work should be acknowledged at the end of the manuscript.

- Authorship should not be granted based on seniority or experience but should be earned by working on the manuscript and given only to persons who deserve it.

- The corresponding author should certify that all authors have fulfilled the required standards for authorship and prepare a brief write-up describing the contribution of each to the manuscript.

- Ghostwriting is emerging as a big problem in medical publications and needs to be addressed. 


\section{References}

1. Author-Wikipedia. Last accessed on 20th April 2020. Available at https://en.wikipedia.org/ wiki/Author. Author.

2. Sharma H, Verma S. Authorship in biomedical research: a sweet fruit of inspiration or a bitter fruit of trade. Trop Parasitol. 2018;8:62-9.

3. Mowatt G, Shirran L, Grimshaw JM, Rennie D, Flanagin A, Yank V, MacLennan G, et al. Prevalence of honorary and ghost authorship in Cochrane reviews. JAMA. 2002;287:2769-71.

4. Recommendations for the Conduct, Reporting, Editing, and Publication of Scholarly Work in Medical Journals Updated December 2019. Author. Last accessed on 20th April 2020. Available on http://www.icmje.org/recommendations/

5. Hess CW, Brückner C, Kaiser T, Mauron A, Wahli W, et al. Scientific integrity Committee of Swiss Academies of arts and sciences. Authorship in scientific publications: analysis and recommendations. Swiss Med Wkly. 2015;145:w14108.

6. Misra DP, Ravindran V, Agarwal V. Integrity of authorship and peer review practices: challenges and opportunities for improvement. J Korean Med Sci. 2018;33:e287.

7. Gasparyan AY. Authorship and contributor ship in scholarly journals. J Korean Med Sci. 2013;28:801-2.

8. Gasparyan AY, Ayvazyan L, Kitas GD. Authorship problems in scholarly journals: considerations for authors, peer reviewers and editors. Rheumatol Int. 2013;33:277-84.

9. Jawad F. Research ethics: authorship and publication. J Pak Med Assoc. 2013;63:1560-2.

10. Bavdekar SB. Authorship issues. Lung India. 2012;29:76-80.

11. Bates T, Anić A, Marušić M, Marušić A. Authorship criteria and disclosure of contributions: comparison of 3 general medical journals with different author contribution forms. JAMA. 2004;292:86-8.

12. Flanagin A, Carey LA, Fontanarosa PB, et al. Prevalence of articles with honorary authors and ghost authors in peer-reviewed medical journals. JAMA. 1998;280:222-4.

13. Shah A, Rajasekaran S, Bhat A, Solomon JM. Frequency and factors associated with honorary authorship in Indian biomedical journals: analysis of papers published from 2012 to 2013. J Empir Res Hum Res Ethics. 2018;13:187-95.

14. Ghajarzadeh M. Guest authors in an Iranian journal. Developing World Bioeth. 2014;14:15-9.

15. World Association of Medical Editors. Policy Statements Prepared by the WAME Editorial Policy Committee. Last accessed 20th April 2020.

16. Juyal D, Thawani V, Thaledi S, Prakash A. The fruits of authorship. Educ Health (Abingdon). 2014;27:217-20.

17. Claxton LD. Scientific authorship. Part 2. History, recurring issues, practices, and guidelines. Mutat Res. 2005;589:31-45.

18. VR, Simon JR. The ethical assignment of authorship in scientific publications: Issues and guidelines. Acad Emerg Med. 2008;15:963-9.

19. Strange K. Authorship: why not just toss a coin? Am J Physiol Cell Physiol. 2008;295:C567-75.

20. Errami M, Garner H. A tale of two citations. Nature. 2008;451:397-9.

21. MK MN, Bradford M, Drazen JM, Hanson B, Howard B, Jamieson KH, et al. Transparency in authors' contributions and responsibilities to promote integrity in scientific publication. Proc Natl Acad Sci U S A. 2018;115:2557-60.

22. Kempers RD. Ethical issues in biomedical publications. Fertil Steril. 2002;77:883-8.

23. Contributor Roles Taxonomy (CRediT) [Updated 2018]. Lasted accessed on 20th April 2020.

24. Representing contributions by CRediT. Lasted accessed on 20th April 2020. Available on https:// blog.f1000.com/2016/02/10/beyond-authorship-recognising-the-cntributions-to-research/.

25. Faulkes Z. Resolving authorship disputes by mediation and arbitration. Res Integr Peer Rev. 2018;3:12.

26. What people are saying about retraction watch. Lasted accessed on 20th April 2020. Available on https://retractionwatch.com/what-people-are-saying-about-retraction-watch/. 
27. Physics paper sets record with more than 5000 authors. Lasted accessed on 20th April 2020. Available on http://esciencenews.com/sources/news.nature/2015/05/18/physics.paper.sets. record.with.more.5000.authors.

28. La Kim J, Diesner J. Co-authorship networks: a directed network approach considering the order and number of co-authors. J Assoc Inf Sci Technol. 2015;66:2685-96.

29. Lapidow A, Scudder P. Shared first authorship. J Med Libr Assoc. 2019;107:618-20.

Open Access This chapter is licensed under the terms of the Creative Commons Attribution 4.0 International License (http://creativecommons.org/licenses/by/4.0/), which permits use, sharing, adaptation, distribution and reproduction in any medium or format, as long as you give appropriate credit to the original author(s) and the source, provide a link to the Creative Commons license and indicate if changes were made.

The images or other third party material in this chapter are included in the chapter's Creative Commons license, unless indicated otherwise in a credit line to the material. If material is not included in the chapter's Creative Commons license and your intended use is not permitted by statutory regulation or exceeds the permitted use, you will need to obtain permission directly from the copyright holder.

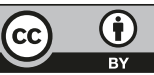

